\title{
ALL IN THE FAMILY OR PUBLIC? LAW AND APPROPRIATIVE COSTS AS DETERMINANTS OF OWNERSHIP STRUCTURE
}

\author{
By \\ Ramon Castillo* and Stergios Skaperdas**
}

\begin{abstract}
We examine how the legal protection of outside shareholders and the appropriative costs that they induce influence the incentives for private firms to go public. A higher degree of protection of shareholders can increase the appropriative costs associated with the conflict between managers and shareholders. To counteract this effect the managers/owners increase the share of the firm they retain so that, overall, higher protection of outsiders increases the likelihood of going public. In addition, we examine how the share of funds raised used to finance the firm affects both appropriative costs and the decision to sell.
\end{abstract}

* California State University, Los Angeles

** Department of Economics, University of California, Irvine, email: sskaperd@uci.edu

For helpful comments we thank participants at the conference on Corporate Governance at UC Irvine (February 2002), seminar participants at the Athens University of Economics and Business, and worskshop participants on the New Organization of Labour at the 2002 CESifo summer Institute in Venice. Skaperdas gratefully acknowledges support from a grant for Research and Writing from the John D. and Catherine T. MacArthur Foundation. 


\section{Introduction}

From Adam Smith to Berle and Means (1933) and Jensen and Meckling (1976), the conflict between outside shareholders and managers has continually received attention as a key factor in the viability of the corporate form of firm organization. For almost a century after the publication of the Wealth of Nations, Adam Smith seemed to have been right about the survival potential of joint stock companies. Since then, however, corporations have taken off as by far the most dominant form of firm organization. What occurred in mid-nineteenth century United States to change the conditions so favorable for corporations? Yet, the conflict between shareholders and managers is far from being a settled issue. The control of managers is apparently very different in Japan and Germany than it is in the U.S. or the U.K., and stock-market valuations relative to GDP per capita vary considerably across countries with similar levels of economic development. And in much of Latin America, Asia, and in almost all developing countries, family control of firms - whether privately owned or nominally public - is still the norm. What accounts, then, for the sudden rise of the corporation, the different forms that it has taken, and the persistence in many parts of the world of seemingly antiquated forms of ownership?

The comparative research undertaken by La Porta et. al. (1998, 1999) suggests a fruitful direction to consider: Law. La Porta et. al. have shown that laws pertaining to the ownership of capital can differ significantly across countries and that could help explain the differing patterns of ownership across them. ${ }^{1}$ At the theoretical level, recent studies have considered the importance of the legal system as a variable that affects the structure of ownership. Burkart, Panunzi, and Shleifer (2002), for example, focus on the importance of the legal strcuture in deciding the delegation of control. Similarly, Burkart and Panunzi (2001) analyze the conflict between large and minority shareholders under an environment of weak legal protection. Using a "crime-punishment" approach, Shleifer and Wolfenzon (2002) develop a model that highlights the effectiveness of the legal system as a factor that deters the level of illegal activities within the firm. In this paper we develop

\footnotetext{
${ }^{1}$ See also Castillo (2002) for evidence from Latin American firms.
} 
a model that takes account of the role of law in shaping the behavior of managers and shareholders and in determining ownership structure.

We consider a private firm owner who contemplates going public. ${ }^{2}$ The decisions to sell and how much to sell depend on how well outside shareholders will be protected and the costs that can be expected to be incurred by both managers and shareholders in determining how much each side receives. We model the conflict between managers and outside shareholders as involving a choice between ordinary production and appropriation, a tradeoff that exists in many other economic settings. ${ }^{3}$ In addition to simply stealing the output or assets of the firm, with the help of either simple or elaborate schemes, managers can engage in many other activities that enhance their compensation and which may not be commonly recognized as such. They can spend time and their staff's time promoting themselves to the press and their shareholders, for hiring supposedly independent compensation consultants who will argue in front of the board of directors for another elaborate compensation scheme that is meant to provide high-powered incentives for the managers but it turns out to increase, rain or shine, the manager's compensation. The manager can spend time in suggesting the selection - if not actually selecting - members of the boards of directors; even if not participating in the selection. In short, the officials of the corporation can use a big chunk of their staff and other company resources to feather their nests without the board of directors being able to show that these resources are used for the benefit of the managers. The resources that managers, board of

\footnotetext{
${ }^{2}$ Zingales (1995), Burkart, Gromb, and Panunzi (1997), and Pagano and Roell (1998) have previously examined the decision of a private firm to go public. Zingales primarily examines the benefits and costs of selling to dispersed shareholders and does not take account of monitoring and other related costs. Burkart, Gromb, and Panunzi take account of monitoring costs but also of the reduction in managerial initiative that monitoring can bring about. Pagano and Roell also take account of these costs, they focus on the tradeoff between selling to dispersed shareholders and have higher liquidity or to small numbers of them who will overmonitor. None of these paper examine the role of law. Finally, Mueller and Warneryd (2001) argue that a private firm would involve more internal conflict than a public firm and, therefore, other things being equal would have less value than a public firm; this provides a complementary rationale to ours for going public.

${ }^{3}$ Other instances of appropriative activities include rent-seeking and lobbying (Tullock, 1980), influence activities within organizations (Milgrom, 1988), litigation (Hirshleifer and Osborne, 2001), common stealing, and of course arming and fighting. We follow much of the relevant literature of the 1990s and model the distributional part of appropriation as a contest (see, e.g., Hirshleifer, 1995, Grossman and Kim, 1995, Rajan and Zingales, 2000, and the overview in Garfinkel and Skaperdas, 2000).
} 
directors, and shareholders expend on appropriative activities are typically non-contractible and therefore difficult or impossible to avoid.

Law and regulation do not and cannot eliminate these costs. In fact, we show that better protection of outside shareholders can actually intensify the competition between managers and shareholders and can increase the costs of appropriation. That is, law and changes to it have both a distributional effect - the relative power of the two sides changes with changes in the law - and a resource-cost effect, as the two sides make different choices about how much to allocate to appropriation in different legal environments. The distributional effect is such that better protection of outsiders will make selling to outsiders easier but the resource-cost effect can nullify and even reverse the distribution effect. To counteract the possibly negative effect on resource costs, the manager/owner will essentially commit to a lower level of appropriative activities by retaining a bigger share of the firm. Overall, however, and although appropriative costs and the share retained by the owner/manager are non-monotonic in the variable that measures increased protection of outside shareholders, the net value to the original owner is monotonic in the same variable. Thus, in the end owners are more likely to go public when outside shareholders are better protected.

Some of the funds that are raised can be used to finance the operations of the firm. What share of the raised funds is thus used and what share is simply pocketed by the owner/managers also affects the amount of appropriative costs and the optimal share retained by the owner/managers. Higher shares going to equity finance, because they increase the gross value of the firm, increase appropriative costs and increase the optimal share retained.

\section{The Basic Framework}

We begin by considering a firm owner who owns a family firm that has value $V_{f}$. This is the maximum value that he could obtain either in the private market by entirely selling and exiting the firm or by continuing as owner. This value is net of any appropriative and influence costs that are due to the internal functioning of the firm (see Milgrom, 1988; Milgrom and Roberts, 1990; and, for the effect on the corporate form of ownership, Mueller and Warneryd, 2001). The owner contemplates raising capital via selling equity. We assume that the owner retains managerial control of the firm because he 
may have expertise that is indispensable to the functioning of the firm. It is often the case that, even when outside shareholders acquire the majority of the firm, the incumbent owner retains some prominent managerial position within the firm. Typically, a firm owner will have first hand knowledge of the daily operations of the firm. In that case, keeping him in the firm, even if he holds a non-managerial position, may be in the best interest of the firm.

If an amount $S$ is raised from selling equity, we assume that a fraction $\gamma \in[0,1]$ is used to finance the activities of the firm and $1-\gamma$ is kept by the owner. The gross value of the firm once it becomes public is $V_{p}(\gamma S)$ and is increasing in the amount of external finance received so that $V_{p}^{\prime}(\gamma S) \geq 0$ (the value of this derivative is assumed to be high enough at sufficiently low levels of $\gamma S$ so as to justify going public in at least some cases). The value of $V_{p}(\gamma S)$ can be greater, equal or smaller than the value of a privately owned firm, $V_{f}$, depending on the benefits and costs of both types of ownership. Our problem becomes relevant, however, when $V_{p}(\gamma S)>V_{f}$. That is, we shall maintain that the gross value of a public firm is higher than the value of the firm when it is solely owned by the family. In addition to the new funds $\gamma S$ that become available, there are several other reasons for which this might be the case. The adoption of accounting standards and other procedures that are required for public firms, but not of family firms, could attract cheaper debt financing, better terms from suppliers and customers, and generally increased public recognition that can materially help the marketing of the firm's products and services. Additionally, following the rationale found in Mueller and Warneryd (2001), the corporate form of organization could free up some resources that are expended on internal struggles within family or other private firms. Of course, this gross value of the public firm is assumed to be net of the underwriting and other costs of going public.

The value $V_{p}(\gamma S)$, however, is not costlessly distributed between shareholders and managers. As mentioned in the introduction, managers and outside shareholders will typically engage in an appropriative struggle to receive a share of the firm's value. Because this struggle is costly, the sum of the payoffs of the outside shareholders will in general be lower than the gross value of the public firm. Managers will undertake costly actions, denoted by $e_{m}$, to appropriate part of the value of the firm, whereas outside shareholders will exert costly effort, denoted by $e_{s}$, to protect their investment. These efforts are non-verifiable and non-contractible. We abstract here from the collective action problem that shareholders face, especially since we have not found a reason that incorporating the free-rider problem would change 
our qualitative results. (Pagano and Roell, 1998, examine some of the issues when there are shareholders with different incentives to monitor the manager.) Moreover, our approach indicates that the problem between managers and shareholders can still be substantial even in the presence of a large shareholder.

The share of the gross value of the public firm received by the manager is a function of the two kinds of effort $q\left(e_{s}, e_{m}\right)$, with the remainder $1-q\left(e_{s}, e_{m}\right)$ going to the shareholders (including the manager himself who keeps a share of the firm). The form that $q\left(e_{s}, e_{m}\right)$ takes is the following:

$$
q\left(e_{s}, e_{m}\right)=\frac{\theta f\left(e_{m}\right)}{\theta f\left(e_{m}\right)+f\left(e_{s}\right)}
$$

where $\theta>0$ and $f(\cdot)$ is a positive, increasing, and strictly concave function. This is an asymmetric contest success function, variations of which have been used in different literatures. The properties of symmetric variants, whereby $\theta=1$, have been examined in Hirshleifer (1989) and axiomatized in Skaperdas (1996). The asymmetric case with $f(e)=e^{k}(k>0)$ has been axiomatized by Clark and Riis (1998). This is also the functional form mostly used in the literatures on rent-seeking contests that began with Tullock (1980), on conflict (Hirshleifer, 1991, Grossman and Kim, 1995), on litigation (Farmer and Pecorino, 1999, Hirshleifer and Osborne, 2001), and on influence contests within firms (Mueller and Warneryd, 2001). Under some conditions, the functional form in (1) can also be derived from a process of Bayesian updating that is described for a particular trial in Kadane and Schum (1996).

Given the properties of $f(\cdot)$ and $\theta$, the share received by the manager, $q\left(e_{m}, e_{s}\right)$, is increasing in his effort $e_{m}$ and decreasing in the effort of the outside shareholders, $e_{s}$, as it obviously should. When $\theta>1$, the managers are favored, in the sense that equal efforts by the two sides will yield a share of $\frac{\theta}{\theta+1}$ for the managers which is greater than $\frac{1}{2}$. Similarly, for $\theta<1$ the outside shareholders have the advantage. Therefore, $\theta$ is an important parameter that is critical for the distribution between managers and outside shareholders of the gross value of the public firm. This is the parameter that represents the state of the law, and the accompanying enforcement capabilities, in helping determine the distribution between the two sides. Typically, we can expect a legal and enforcement system that is more sophisticated and able to protect the outside shareholders better to have a lower value of $\theta$, 
and from now on we will represent the increasing protection of shareholders with a reduction in the value of this parameter.

Let $\alpha \in[0,1]$ denote the share of ownership of the public firm retained by the manager/owner. The struggle between managers and outside shareholders takes place conditional on a particular value of $\alpha$, as well as on a particular value of equity $S$ that has been raised as a result of the sale. Given then the values of $\alpha$ and $S$, the relevant payoff functions for the manager and the outside shareholders are as follows:

$$
\begin{aligned}
V_{m}\left(e_{m}, e_{s} ; \alpha, \gamma S\right) & =\left(q\left(e_{s}, e_{m}\right)+\alpha\left(1-q\left(e_{s}, e_{m}\right)\right)\right) V_{p}(\gamma S)-e_{m} \\
V_{s}\left(e_{m}, e_{s} ; \alpha, \gamma S\right) & =(1-\alpha)\left(1-q\left(e_{s}, e_{m}\right)\right) V_{p}(\gamma S)-e_{s}
\end{aligned}
$$

Note that the manager not only receives a share of the gross value of the firm in his function as manager (corresponding to the share $q\left(e_{s}, e_{m}\right)$ ), but also receives a share in his capacity as shareholder $\left(\alpha\left(1-q\left(e_{s}, e_{m}\right)\right)\right)$. That could theoretically give rise to the possibility of the manager contributing appropriative efforts both as manager and shareholder. It can be readily shown, however, that this possibility could never arise in Nash equilibrium when $\alpha<1$, or when the firm is public. The resulting Nash equilibrium efforts will be functions of $\alpha$ and $\gamma S$, and therefore the equilibrium payoffs of the manager and the shareholders will be functions of $\alpha$ and $\gamma S$ as well. Denote these equilibrium payoffs by $V_{m}^{*}(\alpha, \gamma S)$ and $V_{s}^{*}(\alpha, \gamma S)$.

The decisions of the private firm owner of whether to go public and, if he were to go public, what percentage of the firm to sell, will depend not just on the manager's payoff $V_{m}^{*}(\alpha, \gamma S)$ but also on the amount of money that can be raised, which in turn should depend on the expected payoff that the prospective shareholders can expect to receive $\left(V_{s}^{*}(\alpha, \gamma S)\right)$. To be clear, there are three stages in the game we are examining:

Stage 1: The firm owner decides whether to go public or not.

Stage 2: Conditional on the choice of going public, the manager/owner decides what percentage of the firm, $\alpha$, to retain and what percentage, $1-\alpha$, to sell to outside shareholders.

Stage 3: The manager and outside shareholders engage in a distributional struggle that is described by the payoff functions in (2) and (3). 
For the private firm owner contemplating whether to sell and how much to sell in Stages 1 and 2, the expected payoff from selling includes the equilibrium payoff of the manager/owner of the public firm and the proceeds from selling equity:

$$
V_{o}(\alpha, S)=V_{m}^{*}(\alpha, \gamma S)+(1-\gamma) S
$$

In turn, the proceeds from selling equity will depend on the value that prospective shareholders will receive which is the equilibrium payoff in the third stage of the game. In particular, we suppose that the proceeds from the sale of equity equal the value that the prospective shareholders expect to receive, so that:

$$
S=V_{s}^{*}(\alpha, \gamma S)
$$

This equation implicitly defines the amount raised, $S$, as a function of the share $\alpha$ retained by the manager. Denoting this function by $S(\alpha)$, the ex ante payoff of the private firm owner in (4) can be expressed as a function of only the share of ownership $\alpha$ that he retains:

$$
V_{o}(\alpha, S(\alpha))=V_{m}^{*}(\alpha, \gamma S(\alpha))+(1-\gamma) S(\alpha)
$$

If this value were to be lower than the value of the private firm $V_{f}$ for all $\alpha$, then it would be optimal for the firm to remain private. Otherwise, it would be optimal to go public at the $\alpha$ that maximizes the value in (6). In practice, the percentage of raised that is plowed back into the farm, as signified by $\gamma$, should be a choice variable as well. However, in order to keep the analysis simple enough we examine the optimal choice of $\alpha$ for all $\gamma$. To determine the optimal choice of ownership structure that maximizes the owner's payoff, we first need to examine what occurs when the firm goes public in the third stage.

\section{Managers versus Outside Shareholders}

We consider the Nash equilibrium under the payoff functions in (2) and (3). Given the strict concavity of $f(\cdot)$ in $(1)$, it can be shown that a unique Nash equilibrium exists. We suppose an interior equilibrium $\left(e_{m}^{*}, e_{s}^{*}\right)$, and the firstorder conditions for the two sides imply: 


$$
\begin{aligned}
& \frac{\theta f^{\prime}\left(e_{m}^{*}\right) f\left(e_{s}^{*}\right)}{\left[\theta f\left(e_{m}^{*}\right)+f\left(e_{s}^{*}\right)\right]^{2}}(1-\alpha) V_{p}(\gamma S)=1 \\
& \frac{\theta f^{\prime}\left(e_{s}^{*}\right) f\left(e_{m}^{*}\right)}{\left[\theta f\left(e_{m}^{*}\right)+f\left(e_{s}^{*}\right)\right]^{2}}(1-\alpha) V_{p}(\gamma S)=1
\end{aligned}
$$

Dividing these equations, we obtain

$$
\frac{f^{\prime}\left(e_{m}^{*}\right)}{f\left(e_{m}^{*}\right)}=\frac{f^{\prime}\left(e_{s}^{*}\right)}{f\left(e_{s}^{*}\right)}
$$

which, given the strict concavity of $f(\cdot)$, implies that the two sides exert equal efforts $e_{m}^{*}=e_{s}^{*}$. We will illustrate the basic comparative static results that can be obtained with the widely-used functional form $f(e)=e$. Under this assumption, the equilibrium efforts are as follows:

$$
e_{m}^{*}=e_{s}^{*}=\frac{\theta}{(\theta+1)^{2}}(1-\alpha) V_{p}(\gamma S)
$$

The first property to note is that the appropriative efforts of both sides are non-monotonic in the legal variable $\theta$. In particular, when $\theta>1$, and the manager is favored, the effort is increasing as $\theta$ decreases and the rights of shareholders become more secure. Appropriative efforts reach their maximal level at $\theta=1$. With $\theta<1$, the appropriative efforts are decreasing as $\theta$ decreases and the rights of shareholders become more secure.

Given that the gross value of the public firm, $V_{p}(\gamma S)$, is fixed at this stage, the net value of the firm varies solely with the size of the appropriative efforts and is inversely related to their size. Therefore, the property of non-monotonicity in the legal variable $\theta$ implies that the net value of the public firm is non-monotonic in the legal variable as well. That is, improvements in the legal system in favor of shareholders over certain ranges increase appropriative costs and reduce the net value of the public firm. For improvements in the legal system to reduce appropriative costs and increase firm value, outside shareholders should be sufficiently favored already. As an example of how this theoretical finding might be useful, consider Russia in the 1990s. As amply documented (Blasi et al, 1997, Klebnikov, 2000), in the privatized enterprises insiders left very little, if anything, to outside shareholders and they did so mostly legally and without fuss. There was nothing for outsiders to do and contest this process and there was no need for insiders to seriously 
counter the efforts of outsiders. With the slowly-introduced measures that provide some added protection to outside shareholders, however, there is no guarantee that the conditions will improve and, on the contrary, they can be expected to intensify the struggle between the two sides in a way that could make the net values of public firms lower than they were earlier. In fact, outside investors in Russia realized this rather quickly and apparently much of the stock is actually owned by insiders now, as a partial remedy to the problem.

Predictably, then, as can be easily inferred from (9), a larger share of the firm held by the manager, $\alpha$, unambiguously reduces the appropriative efforts of both the manager and the outside shareholders; obviously, the interests of the two parties become more aligned as the manager has a greater stake in the firm. Finally, note that an increase in the amount of equity financing that is plowed back into the firm (that is, an increase in $\gamma S$ ), by increasing the gross value of the firm $V_{p}(\gamma S)$ and the prize the two sides contest, also increases their appropriative efforts and negates some of the increase brought about by the increased financing.

Given the equilibrium appropriative efforts in (9), we can straightforwardly calculate the equilibrium payoffs of the manager and the outside shareholders in this third stage of the game:

$$
\begin{aligned}
V_{m}^{*}(\alpha, \gamma S) & =\frac{\alpha+2 \alpha \theta+\theta^{2}}{(\theta+1)^{2}} V_{p}(\gamma S) \\
V_{s}^{*}(\alpha, \gamma S) & =\frac{1-\alpha}{(\theta+1)^{2}} V_{p}(\gamma S)
\end{aligned}
$$

Though the total net surplus is non-monotonic in the legal variable $\theta$, the equilibrium payoffs of the two sides can be shown to be monotonic, and in predictable ways: As $\theta$ decreases, and the outside shareholders become more favored, the equilibrium payoff of the manager decreases and that of the outsiders increases. As the share of the manager in the firm, $\alpha$, increases, his equilibrium payoff increases for two reasons: Because he claims a bigger share of the share of shareholders and because his appropriative costs are lower. The effect of $\alpha$ on the outside shareholders is straightforward as well: it reduces their payoff as they have less to claim from the shareholders' share with the reduction in their appropriative costs not, obviously, being higher than their reduced share. Finally, the effect of equity financing, $\gamma S$, is to increase the payoffs of both sides. 


\section{How much to sell?}

Given the choices that can be expected to be made by the manager and the outside shareholders in the third stage, the prospective manager and current owner makes the choice of what percentage, $\alpha$, to retain of the firm. That is, he maximizes $V_{o}(\alpha, S(\alpha))$ in $(6)$.

It is instructive to first briefly consider the simpler case in which the owner/manager receives all the proceeds of the sale and no funds are reinvested (i.e., $\gamma=0$ ). In that case, the gross value of the public firm is $V_{p}(0)$, which given that $V_{p}(\gamma S)$ is increasing in its argument (external finance), is the lowest possible value that it can take. Furthermore, the amount of external finance is easier to obtain from (6) and equals $S(\alpha)=V_{s}^{*}(\alpha, 0)$. Then, the owner's objective function becomes

$$
V_{o}(\alpha, S(\alpha))_{\gamma=0}=V_{m}^{*}(\alpha, 0)+V_{s}^{*}(\alpha, 0)
$$

Note that this equals the net surplus of the public firm, or

$$
V_{o}(\alpha, S(\alpha))_{\gamma=0}=V_{p}(0)-e_{m}^{*}-e_{s}^{*}
$$

Since the equilibrium efforts are inversely related to $\alpha$, the maximal choice is to set $\alpha^{*}=1$. This is of course a limiting case that should not take place because the owner would simultaneously have his cake intact (i.e., have his company be a corporation and have all the benefits and the valuation from being a corporation) and eat his cake too (i.e., have the firm be completely owned by him). ${ }^{4}$

From now on, then, we suppose $\gamma>0$. The total amount raised from outside shareholders as a function of insider ownership, $S(\alpha)$, is implicitly defined in (5). For simplicity we will consider $f(e)=e$, which yields the equilibrium payoff functions in (10) and (11) and implies:

$$
S^{\prime}(\alpha)=\frac{V_{p}(\gamma S(\alpha))}{(1-\alpha) \gamma V_{p}^{\prime}(\gamma S(\alpha))-(\theta+1)^{2}}
$$

Provided that the gross value of the firm does not increase too fast with the amount of equity financing (in particular, $V_{p}^{\prime}(\gamma S(\alpha))<\frac{(\theta+1)^{2}}{(1-\alpha) \gamma}$ ), the value of this derivative is negative. Naturally, that is, the amount raised from outside shareholders is increasing in the share of ownership sold to them.

\footnotetext{
${ }^{4}$ We can rule out that this possibility will occur by supposing thar $V_{f} \geq V_{p}(0)$.
} 
Similarly, it can be shown that the amount raised from outside shareholders increases as the law becomes more favorable to outside shareholders. (That is, $S(\alpha)$ is decreasing in $\theta$.)

Along with (10), the ex ante value to the owner as a function of his share $\alpha$ in (6) becomes:

$$
V_{o}(\alpha, S(\alpha))=\frac{\alpha+2 \alpha \theta+\theta^{2}}{(\theta+1)^{2}} V_{p}(\gamma S(\alpha))+(1-\gamma) S(\alpha)
$$

The marginal benefits and costs of changing the manager's share of ownership can be determined by differentiating (13):

$$
\begin{aligned}
\frac{\partial V_{o}(\alpha, S(\alpha))}{\partial \alpha}= & \frac{(1+2 \theta)}{(\theta+1)^{2}} V_{p}(\gamma S(\alpha)) \\
& +\left[\frac{\alpha+2 \alpha \theta+\theta^{2}}{(\theta+1)^{2}} V_{p}^{\prime}(\gamma S(\alpha) \gamma+(1-\gamma))\right] S^{\prime}(\alpha)
\end{aligned}
$$

The first term on the right-hand-side represents the marginal benefit of keeping a higher share of the firm and consists of two distinct components that we discussed in the previous section: A higher share increases the part of the value of the firm claimed and it reduces appropriative costs. The second term on the right-hand-side of (14) represents the marginal cost of increasing the manager's share of the firm and has two distinct components as well. First, a higher share of the firm retained by the manager reduces equity financing which reduces the total gross value of the public firm. This component is reflected in the first term inside the square brackets. Second, reflected in the second term inside the brackets, a higher share retained by the manager simply reduces the sale proceeds received by him.

Provided the optimal $\alpha^{*} \in(0,1)$, it can be obtained by setting (14) equal to $0 .{ }^{5}$ As the equilibrium appropriative efforts and the net surplus in stage 3 are non-monotonic in the legal variable $\theta$, so is the choice of $\alpha^{*}$. To illustrate this monotonicity we consider the following Cobb-Douglas-like form of the gross value of the public firm:

$$
V_{p}(\gamma S)=K(\gamma S)^{1 / 2} \text { where } K>0
$$

\footnotetext{
${ }^{5}$ The concavity of $V_{o}(\alpha, S(\alpha))$ in $\alpha$ is guaranteed when $V_{p}^{\prime \prime}(\cdot)<0$. This condition also guarantees that $S^{\prime \prime}(\alpha)$ in (13) is negative.
} 
Then, using (11), the following specific form of $S(\alpha)$ can be found from $(5)$ :

$$
S(\alpha)=\gamma \frac{(1-\alpha)^{2}}{(\theta+1)^{4}} K^{2}
$$

The specific value of $V_{o}(\alpha, S(\alpha))$ can then be obtained:

$$
V_{o}(\alpha, S(\alpha))=\gamma K^{2} \frac{(1-\alpha)}{(\theta+1)^{4}}\left[\alpha(1+2 \theta)+\theta^{2}+(1-\gamma)(1-\alpha)\right]
$$

Then, the optimal share of ownership by the manager is:

$$
\alpha^{*}=\frac{2 \gamma-(1-\theta)^{2}}{2(2 \theta+\gamma)}
$$

provided, of course, that $2 \gamma>(1-\theta)^{2}$; otherwise $\alpha^{*}=0 .{ }^{6}$ Note that this optimal share of the manager is increasing in the share of funds raised $\gamma$ that are used to finance the firm. A higher $\gamma$ increases the gross value of the firm and, in the stage of struggle between the manager and outside shareholders, increases appropriative costs. To counteract this effect, the owner/manager has to increases his share of the firm that he retains.

The effect of the legal variable $\theta$, however, is again non-monotonic. It can be shown that when the manager is sufficiently favored so that $\theta>$ $1-\gamma$, improvements in the protection of shareholders increase the optimal share held by the manager (i.e., $\frac{\partial \alpha^{*}}{\partial \theta}<0$ ). A significant component of this effect comes from the increased appropriative costs that accompany such (insufficiently effective) improvements in the rights of outside shareholders and the need on the part of the manager to counteract it by increasing his share. This effect is stronger when the share of equity financing $\gamma$ is higher. Only when outside shareholders are sufficiently favored already ( $\theta<1-\gamma)$ does the optimal share held by the manager begin to decline with improvements in the rights of shareholders (i.e., $\frac{\partial \alpha^{*}}{\partial \theta}>0$ ).

\footnotetext{
${ }^{6}$ Note that in the case of $\gamma=0$, discussed earlier, the expression below would imply that $\alpha^{*}$ should be 0 , not 1 . The reason for this difference is that according to $(15), V_{p}(0)=0$, something that we implicitly did not allow for in the earlier discussion. As we shall see below, if $\gamma$ were to vary freely and be a choice variable, it would be optimal to set it equal to 1 in this case.
} 


\section{The Decision to Go Public}

The optimal share that the owner would sell to outside shareholders determines the value to the owner of going public and equals $V_{o}\left(\alpha^{*}, S\left(\alpha^{*}\right)\right)$. The owner then will go public if and only if

$$
V_{o}\left(\alpha^{*}, S\left(\alpha^{*}\right)\right) \geq V_{f}
$$

Under the example we have followed, with $f(e)=e$ and $V_{p}(\gamma S)=$ $K(\gamma S)^{1 / 2}$ in (15), the maximal value of going public to the owner equals

$$
V_{o}\left(\alpha^{*}, S\left(\alpha^{*}\right)\right)=\frac{K^{2} \gamma}{8(2 \theta+\gamma)}
$$

Note that, although both appropriative costs and the optimal ownership share are non-monotonic in the legal variable $\theta$, this value of going public is monotonic in the same variable. Increased protection of shareholders (i.e., reductions in $\theta$ ) unambiguously increase the value of going public to the owner and therefore make it more likely that (19) will be satisfied and going public will be optimal. Despite the increased appropriative costs that accompany the increased protection of shareholders over a certain range, the value the owner receives increases because the owner counteracts this effect on appropriative costs by increasing his share of the firm that he retains. Moreover, the higher share of the owner and the lower share of outside shareholders that can accompany reductions in $\theta$ does not imply lower value received by the outside shareholders. For the latter's payoff, which also equals the total amount of funds raised, can be shown to equal $\frac{\gamma K^{4}}{4(\theta+1)^{2}(2 \theta+\gamma)^{2}}$; this is clearly decreasing in $\theta$ and thus increasing in improvements in the protection of shareholders.

Thus, from (20) we can infer that going public is more likely (i) the higher is the protection of outsider shareholders (lower $\theta$ ); (ii) the lower is the value of the family firm $V_{f}$; (iii) the higher is the advantage of public firms over private firms, as captured by the parameter $K$; and (iv) the higher is equity financing as a percentage of the total funds raised (i.e., the higher is $\gamma$ ).

This last property implies that, if the percentage of equity financing were a choice variable for the owner/manager, it would be optimal for him to choose the maximal percentage of equity financing possible or set $\gamma=1$. That, by (18) and to partly counteract the increased appropriative costs 
brought about by the higher gross value of the public firm, would also imply a higher optimal share of ownership for the manager.

Property (iv), however, and the implication just discussed does not appear to be quite general. It depends on the effect of equity financing on the gross value of the public firm being strong enough (i.e, having a high enough $V_{p}^{\prime}(\gamma S)$ ). If that effect were not to be strong enough, we would expect the optimal percentage of equity financing to be strictly less than 1 .

\section{Concluding Remarks}

Although in this paper we have freely varied the parameter that captures the degree of legal protection of outside shareholders, we do not mean to imply that changing that legal protection is easy and costless in practice. Besides the private costs to the issuer of stock, laws change very slowly and their enforcement is far from being a trivial matter. Such legislation is highly complex and formulating it and passing it in a manner consistent with a country's existing legal framework is but a small initial step. Other prerequisites include appropriate registries, courts and enforcement agencies, and an infrastructure of accountants, lawyers, their teachers, and other professionals. Additionally, all the steps that one has to go through in issuing, selling and transferring of stock, in litigation, and in enforcement have to be close to 100 percent free of corruption, a rather tall order in most countries even today. Finally, all the participants have to be confident that no radical change can be expected in any of the laws or their enforcement. Thus, changes in the legal protection of outsiders can only be small at any particular time, something that helps us explain the diversity of ownership forms that are observed around the world. 


\section{REFERENCES}

Berle, Adolf A., and Gardiner C. Means, The Modern Corporation and Private Property, 1933, New York: Macmillan.

Blasi, Joseph R., Kroumova, Maya, and Kruse, Douglas, Kremlin Capitalism: Privatizing the Russian Economy, 1997, Ithaca, NY: Cornell University Press.

Burkart, Mike and Fausto Panunzi. "Agency Conflicts, Ownership Concentration and Legal Shareholder Protection." Financial Markets Group (LSE) Discussion Paper 378 (2001).

Burkart, Mike, Fausto Panunzi and Andrei Shleifer. "Family Firms." NBER Working paper 8776, (2002).

Burkart, Mike, Denis Gromb and Fausto Panunzi. "Large Shareholders, Monitoring, and the Value of the Firm." Quarterly Journal of Economics, 112 (1997): 693-728.

Castillo, Ramon A. "La Protección de los Derechos de Propiedad y la Elección de la Estructura de la Propiedad Corporativa," El Trimestre Economico (2002) 273: 37-64.

Clark, Derek, and Christian Riis. "Contest Success Function: An Extension." Economic Theory, January 1998, 11(1): 201-204.

Demsetz, Harold, and Kenneth Lehn. "The Structure of Corporate Ownership: Causes and Consequences. "Journal of Political Economy 93 (1985): 1155-1177.

Farmer, A. and O. Pecorino (1999) "Legal Expenditure as a Rent Seeking Game", Public Choice, September, 100: 271 - 288.

Garfinkel, Michelle R. and Skaperdas, Stergios, "Contract or War? On a the Consequences of a Broader Biew of Self Interest in Economics," American Economist, Spring 2000, 44(1): 5-14.

Hart, Oliver, Firms Contracts and Financial Structure, 1995, Oxford: Clarendon Press

Grossman, Herschel I. and Kim, Minseong, "Swords or Plowshares? A Theory of the Security of Claims to Property," Journal of Political Economy, December 1995, 103(6), 1275-1288. 
Hirshleifer, Jack. "Conflict and Rent-Seeking Success Functions: Ratio vs. Difference Models of Relative Success." Public Choice, 63 (1989): 101-112.

Hirshleifer, Jack, "Anarchy and its Breakdown," Journal of Political Economy, February 1995.

Hirshleifer, Jack and Osborne, Evan, "Truth and the Legal Battle," Public Choice, July 2001, 108(1-2): 169-195.

Jensen, Michael C., and William H. Meckling. "Theory of the Firm: Managerial Behavior, Agency Costs and Ownership Structure." Journal of Financial Economics 3 (1976): 305-360.

Kadane, Joseph and Schum, David, A Probabilistic Analysis of the Sacco and Vanzetti Evidence, 1996, New York: Wiley-Interscience.

Klebnikov, Paul, Godfather of the Kremlin: The Decline of Russia in the Age of Gangster Capitalism, 2000, New York: Harcourt Inc.

La Porta, Rafael, Florencio Lopez-de-Silanes, Andrei Shleifer, and Robert Vishny, "Law and Finance," Journal of Political Economy, December 1998, 106(6), 1113-1155.

La Porta, Rafael, Florencio Lopez-de-Silanes, Andrei Shleifer, and Robert Vishny. "Corporate Ownership Around the World." Journal of Finance, 54 (1999): 471-517.

Milgrom, Paul R. "Employment Contracts, Influence Activities, and Efficient Organization Design." Journal of Political Economy, 96 (1988): 42-61.

Milgrom, Paul and Roberts, John, "The Efficiency of Equity in Organizational Decision Processes," American Economic Review, Papers and Proceedings, May 1990, 154-159.

Mueller, Holger and Warneryd, Karl, "Inside Versus Outside Ownership: A Political Theory of the Firm," RAND Journal of Economics, Fall 2001, 32(3), 527-541.

Pagano, Marco, and Ailsa Roell. "The Choice of Stock Ownership Structure: Agency Costs, Monitoring, and the Decision to Go Public." Quarterly Journal of Economics, 113 (1998):187-225.

Rajan, Raghuram G. and Zingales, Luigi, "The Tyranny of Inequality," Journal of Public Economics, June 2000, 76, 521-558. 
Shleifer, Andrei, and Robert W. Vishny. "A Survey of Corporate Governance." Journal of Finance, 52 (1997): 737-783.

Shleifer, Andrei and Daniel Wolfenzon. "Investor Protection and Equity Markets." Journal of Financial Economics, 66 (2002): $3-27$

Skaperdas, Stergios. "Contest Success Functions. "Economic Theory 7 (1996): 283-290.

Tullock, Gordon (1980). "Efficient Rent Seeking," in J.M. Buchanan, R.D. Tollison, and G. Tullock (eds), Toward a Theory of the Rent Seeking Society, College Station: Texas A\&M University Press: 355-372.

Zingales, Luigi. "Insider Ownership and the Decision to Go Public." Review of Economic Studies, 62 (1995): 425-448. 